\title{
A comparative study to evaluate the risk factors for patients admitted with community acquired pneumonia in pediatrics department of people's hospital Bhopal, Madhya Pradesh, India
}

\author{
Mekle D. ${ }^{1}$, Dwivedi P. ${ }^{2 *}$, Dixit J. ${ }^{3}$ \\ DOI: https://doi.org/10.17511/ijpr.2021.i01.04
}

1 Dinesh Mekle, Associate Professor, Department of Pediatrics, Peoples College of Medical Science and Research Centre, Bhopal, Madhya Pradesh, India.

2* Pratyush Dwivedi, PG Resident, Department of Pediatrics, Peoples College of Medical Science and Research Centre, Bhopal, Madhya Pradesh, India.

3 Jagdamba Dixit, Professor and HOD, Department of Pediatrics, Peoples College of Medical Science and Research Centre, Bhopal, Madhya Pradesh, India.

Aim: To evaluate the risk factors associated with Community Acquired Pneumonia (CAP) in patients admitted to the Pediatric department of People's Hospital Bhopal (MP). Methodology: This was a case-control study which compared patients of CAP aged 2 months to 60 months, admitted in Pediatric department of People's Hospital with children attending well-baby and immunization clinic of People's hospital. Risk factors that were evaluated included demographic, socioeconomic, housing, past and family history, birth variables, nutritional variables, immunization, delay in presentation and previous treatment. Result: The study enrolled in 209 cases and 209 unmatched controls. Male gender, significant past and family history, lower socioeconomic status, poor housing, indoor smoke, overcrowding, incomplete immunization and malnutrition were associated with increased risk of CAP. Previous treatment and delayed presentation were associated with increasing severity of CAP. Conclusion: Concentrated efforts are needed in a direction to reduce the risk factors associated with CAP to prevent the major cause of death of children younger than 5 years.

Keywords: Children 2 months to 60 months, Community-acquired pneumonia, Risk factors

\section{Corresponding Author}

Pratyush Dwivedi, PG Resident, Department of Pediatrics, Peoples College of Medical Science and Research Centre, Bhopal, Madhya Pradesh, India. Email: pratyushdwivedi111990@gmail.com
How to Cite this Article

To Browse

Mekle D, Dwivedi P, Dixit J. A comparative study to evaluate the risk factors for patients admitted with community acquired pneumonia in pediatrics department of people's hospital Bhopal, Madhya Pradesh, India. Pediatric Rev Int J Pediatr Res. 2021;8(1):23-28.

Available From

https://pediatrics.medresearch.in/index.php/ijpr/arti cle/view/654
Manuscript Received 2021-01-12

Conflict of Interest No (c) 2021 by Dinesh Mekle, Pratyush Dwivedi, Jagdamba Dixit and Published by Siddharth Health Research and Social Welfare
Society. This is an Open Access article licensed under a Creative Commons Attribution 4.0 International License https://creativecommons.org/licenses/by/4.0/ unported [CC BY 4.0].

Accepted 2021-02-28 2021-01-22

Funding

eview Round 2 2021-02-10

Review Round 3

Note 


\section{Introduction}

Pneumonia is the term used to describe inflammation of the lung. The World Health Organization defines pneumonia as an acute disease episode with cough combined with fast breathing with age-specific cutoff-values for increased respiratory rate1. Pneumonia is a common illness that affects millions of people each year globallyz. Community-acquired pneumonia (CAP) is a major public health issue and a principal cause of morbidity and mortality in children under 5 years of age3. According to UNICEF 2019 report pneumonia claimed 8 lakh lives in under 5 years of age and out of which 1.27 lakh were from India which is 2 nd highest in the world4. Pneumonia has been identified as the major "forgotten killer of children" by the United Nations Children's Fund (UNICEF) and the World Health Organization (WHO)5.

Pneumonia can affect anyone however, it has been observed that children are at a higher risk of developing the disease than others. There are many risk factors which have been associated with the increased chances of CAP in children6 namely indoor air pollution, malnutrition, lack of breastfeeding, low maternal education, low socioeconomic status (SES), poor access to health care, and concomitant illnesses etc. The purpose of our study is to determine the risk factors associated with childhood CAP in developing countries like India which has implemented many welfare and health programs in the last decade. The controlled and modified control of these risk factors can be used in the future to reduce the mortality and morbidity caused by pneumonia in India.

\section{Objectives}

01. To assess the risk factors in children with pneumonia.

02. To compare the risk factors in children with pneumonia and those without pneumonia.

03. To determine the strength of association of the risk factors in children with pneumonia and those without pneumonia.

04. To assess the severity of pneumonia to various risk factors.

\section{Methodology}

Setting: This questionnaire-based case-control study was conducted in Peoples Hospital Bhopal.
Duration: One and a half year between 1st December 2018 to 30th June 2020

Sampling method: Patients of CommunityAcquired Pneumonia aged 2 months to 60 months who were admitted to the Paediatrics department of People's Hospital Bhopal were taken as cases. One unmatched control per case was taken from healthy children between the ages of 2 months to 60 months of age visiting the well-baby and immunization clinic of Peoples Hospital, Bhopal.

Sample size: All the cases of community-acquired Pneumonia aged 2 months to 60 months who were admitted to the Paediatric department of People's Hospital Bhopal during the study period.

Inclusion criteria: As per WHO classification1, All patients with pneumonia and severe pneumonia aged 2 months to 60 months requiring admission.

Exclusion criteria: Infants aged less than 2 months, Children aged more than 60 months,

Patients of WHO classified pneumonia as requiring admission but were denied by parents.

Data collection procedure- Written consent from the parents was taken before enrolling the child on the study after that a questionnaire was administered. Risk factors that were evaluated included demographic, socioeconomic variables, housing, significant past and family history, birth variables, nutritional variables, immunization, delayed presentation, and previous treatments.

Ethical consideration and the permission: This study was started after obtaining ethical clearance from the Institutional Ethics Committee

Statistical analysis- Data was compiled using Ms Excel and analyzed using SPSS 20 software. Percentage and mean were calculated. A Chi-square test was applied to study the association.

\section{Results}

In the present study, $67 \%$ of males were infected with CAP in contrast to $33 \%$ of females. The majority of the cases (73\%) belonged to the urban locality. Lower socioeconomic status, lower maternal and paternal education, overcrowding and indoor air pollution were associated with CAP. Basic sanitation facilities were found to be better in control groups. Birth order of 3 or more, vaginal, non-institutional, preterm deliveries, significant past and family history were significantly associated with CAP. 
Failure to exclusively breastfeed the baby for 6 months, bottle feeding, malnutrition and incomplete immunization were significantly associated with CAP.
The severity of pneumonia was also analyzed in the present study for different risk factors. Delayed presentation and previous treatment were the two factors found to increase the severity of pneumonia.

TABLE-1: DISTRIBUTION OF DEMOGRAPHIC VARIABLES

(case $\mathrm{n} 1=209$; control $\mathrm{n} 2=209$; total $\mathrm{n}=418$ )

\begin{tabular}{|c|c|c|c|c|c|c|}
\hline \multicolumn{2}{|c|}{ Variable } & CASE(\%) & CONTROL(\%) & TOTAL (\%) & CHI-SQUARE & p-VALUE \\
\hline \multirow{2}{*}{ Age } & $<1 \mathrm{yr}$ & $120(57.4)$ & $132(63.2)$ & $252(60.2)$ & \multirow[t]{2}{*}{1.43} & \multirow{2}{*}{0.23 (NS) } \\
\hline & $>1 Y R$ & $89(42.6)$ & $77(36.8)$ & $166(39.8)$ & & \\
\hline \multirow[t]{2}{*}{ Gender } & Male & $142(67.8)$ & $108(51.6)$ & $250(59.8)$ & \multirow[t]{2}{*}{11.505} & \multirow[t]{2}{*}{0.0007 (HS) } \\
\hline & FEMALE & $67(32.2)$ & $101(48.4)$ & $168(40.2)$ & & \\
\hline \multirow[t]{2}{*}{ Locality } & Rural & $58(27.2)$ & $30(14.4)$ & $88(21.05)$ & \multirow[t]{2}{*}{418} & \multirow[t]{2}{*}{0.0001 (HS) } \\
\hline & URBAN & $151(72.8)$ & $172(85.6)$ & $330(78.95)$ & & \\
\hline
\end{tabular}

TABLE-2: DISTRIBUTION OF SOCIOECONOMIC VARIABLES

(case $n 1=209$; control $n 2=209$; total $n=418$ )

\begin{tabular}{|c|c|c|c|c|c|c|}
\hline \multicolumn{2}{|c|}{ Variable } & \multirow{2}{*}{$\begin{array}{l}\text { Case }(\%) \\
0\end{array}$} & \multirow{2}{*}{$\begin{array}{l}\text { Control( }(\%) \\
0\end{array}$} & \multirow{2}{*}{$\begin{array}{ll} & \text { Total }(\%) \\
0 & \\
\end{array}$} & \multirow{2}{*}{\begin{tabular}{|l} 
Chi-Square \\
74.9
\end{tabular}} & \multirow{2}{*}{$\frac{\text { P-Value }}{0.0003 \text { (HS) }}$} \\
\hline Socio Economic Class & Upper & & & & & \\
\hline & Upper Middle & $39(18.6)$ & $91(43.4)$ & 13031.1 & & \\
\hline & Lower Middle & $67(32.1)$ & 94 (44.9) & 16138.52 & & \\
\hline & Upper Lower & $100(47.8)$ & $24(11.4)$ & $124(29.67)$ & & \\
\hline & Lower & $3(1.4)$ & 0 & $3(0.72)$ & & \\
\hline \multirow[t]{2}{*}{ Over Crowding } & Present & $122(60.4)$ & $16(7.6)$ & $138(33.01)$ & \multirow[t]{2}{*}{121.549} & \multirow[t]{2}{*}{$0.0001(\mathrm{HS})$} \\
\hline & Absent & $87(41.6)$ & $193(92.4)$ & $280(66.99)$ & & \\
\hline \multirow[t]{2}{*}{ Indoor Smoke } & Present & $90(43.2)$ & $24(12.6)$ & $114(27.27)$ & \multirow[t]{2}{*}{52.539} & \multirow[t]{2}{*}{0.0014 (HS) } \\
\hline & Absent & $119(56.8)$ & $185(88.4)$ & $304(72.73)$ & & \\
\hline
\end{tabular}

TABLE-3: ASSOCIATION OF SIGNIFICANT PAST HISTORY, FAMILY HISTORY WITH CAP

(case $\mathrm{n} 1=209$; control $\mathrm{n} 2=209$; total $\mathrm{n}=418$ )

\begin{tabular}{|c|c|c|c|c|c|c|}
\hline \multicolumn{2}{|c|}{ Variable } & Case(\%) & Control(\%) & Total (\%) & Chi-Square & P-Value \\
\hline \multirow[t]{2}{*}{ SIGNIFICANT PAST HISTORY } & PRESENT & $97(46.4)$ & $23(11)$ & $120(28.8)$ & \multirow[t]{2}{*}{64.009} & \multirow[t]{2}{*}{0.0014 (HS) } \\
\hline & ABSENT & $112(53.6)$ & $186(89)$ & $298(71.2)$ & & \\
\hline \multirow[t]{2}{*}{ SIGNIFICANT FAMILY HISTORY } & PRESENT & $34(16.2)$ & $8(3.8)$ & $42(10.1)$ & \multirow[t]{2}{*}{17.893} & \multirow[t]{2}{*}{0.0000 (HS) } \\
\hline & ABSENT & $175(83.8)$ & 201(96.2) & $376(89.9)$ & & \\
\hline
\end{tabular}

TABLE-4: ASSOCIATION OF NUTRITION AND IMMUNIZATION WITH CAP

(case $\mathrm{n} 1=209$; control $\mathrm{n} 2=209$; total $\mathrm{n}=418$ )

\begin{tabular}{|c|c|c|c|c|c|c|}
\hline \multicolumn{2}{|c|}{ Variable } & \multirow{2}{*}{\begin{tabular}{|c|} 
Case(\%) \\
$130(62.2)$
\end{tabular}} & \multirow{2}{*}{\begin{tabular}{|c|} 
Control(\%) \\
$177(84.6)$
\end{tabular}} & \multirow{2}{*}{\begin{tabular}{|l|} 
Total $(\%)$ \\
$307(73.4)$
\end{tabular}} & \multirow{2}{*}{\begin{tabular}{|l} 
Chi-Square \\
27.096
\end{tabular}} & \multirow{2}{*}{$\begin{array}{r}\text { P-Value } \\
0.0011 \text { (HS) }\end{array}$} \\
\hline Ebf For 6 Months & Yes & & & & & \\
\hline & NO & $79(37.8)$ & $32(15.2)$ & $111(26.6)$ & & \\
\hline \multirow[t]{3}{*}{ Weight For Age } & $>-2 s d$ & $105(50.3)$ & $193(92.4)$ & $298(71.2)$ & \multirow[t]{3}{*}{123.017} & \multirow[t]{3}{*}{0.0004 (HS) } \\
\hline & $-2 S D$ TO $-3 S D$ & $50(23.9)$ & $16(7.6)$ & $66(15.8)$ & & \\
\hline & $\mid<-3 S D$ & $54(25.8)$ & 0 & $54(12.9)$ & & \\
\hline \multirow[t]{2}{*}{ Immunization } & Complete & $150(71.8)$ & $197(94.4)$ & $347(83.01)$ & \multirow[t]{2}{*}{37.479} & \multirow[t]{2}{*}{0.0001 (HS) } \\
\hline & INCOMPLETE & $59(28.2)$ & $12(5.6)$ & $71(16.99)$ & & \\
\hline
\end{tabular}

TABLE-5: ASSOCIATION OF SEVERITY OF PNEUMONIA WITH DIFFERENT RISK FACTORS

(severe pneumonia $\mathrm{n} 1=137$; pneumonia $\mathrm{n} 2=72$; total $\mathrm{n}=209$ )

\begin{tabular}{|c|c|c|c|c|c|c|}
\hline \multicolumn{2}{|c|}{ Variable } & Severe Pneumonia (\%) & Pneumonia (\%) & Total (\%) & Chi-Square & P-Value \\
\hline \multirow{2}{*}{$\begin{array}{l}\text { Significant } \\
\text { Past } \\
\text { History }\end{array}$} & Present & $68(70.01)$ & $29(29.99)$ & $97(100)$ & \multirow[t]{2}{*}{1.662} & \multirow[t]{2}{*}{0.197 (NS) } \\
\hline & Absent & $69(61.6)$ & $43(38.4)$ & $112(100)$ & & \\
\hline
\end{tabular}


Mekle D. et al: A comparative study to evaluate the risk factors

\begin{tabular}{|c|c|c|c|c|c|c|}
\hline \multirow[t]{3}{*}{ Weight For Age } & $>-2 \mathrm{Sd}$ & $65(61.9)$ & $40(38.1)$ & $105(100)$ & \multirow[t]{3}{*}{2.163} & \multirow[t]{3}{*}{0.539 (NS) } \\
\hline & -2 To $-3 \mathrm{Sd}$ & $35(70)$ & $15(30)$ & $50(100)$ & & \\
\hline & $<-3 s d$ & $37(68.5)$ & $17(31.5)$ & $54(100)$ & & \\
\hline \multirow[t]{2}{*}{ Overcrowding } & Present & $79(64.75)$ & $43(35.25)$ & $122(100)$ & \multirow[t]{2}{*}{0.082} & \multirow[t]{2}{*}{0.774 (NS) } \\
\hline & Absent & $58(66.66)$ & $29(33.44)$ & $87(100)$ & & \\
\hline \multirow[t]{2}{*}{ Indoor Smoke } & Present & $64(71.1)$ & $26(28.9)$ & $90(100)$ & \multirow[t]{2}{*}{2.165} & \multirow[t]{2}{*}{0.141 (NS) } \\
\hline & Absent & $73(61.3)$ & $46(38.7)$ & $119(100)$ & & \\
\hline \multirow{2}{*}{$\begin{array}{l}\text { Available } \\
\text { Nearby } \\
\text { Health } \\
\text { Facility }\end{array}$} & Present & $73(64.03)$ & $41(35.97)$ & $114(100)$ & \multirow[t]{2}{*}{0.255} & \multirow[t]{2}{*}{0.614 (NS) } \\
\hline & Absent & $64(67.36)$ & $31(32.63)$ & $95(100)$ & & \\
\hline $\begin{array}{l}\text { Previously } \\
\text { Treated }\end{array}$ & Yes & $96(78.04)$ & $27(21.96)$ & $123(100)$ & 20.678 & 0.0021 (HS) \\
\hline \multirow[t]{3}{*}{ Duration of Illness before admission } & $1-3 D$ & $36(53.7)$ & $31(46.3)$ & $67(100)$ & \multirow[t]{3}{*}{6.694} & \multirow[t]{3}{*}{$0.0350(\mathrm{~S})$} \\
\hline & 4-7D & $86(69.9)$ & $37(31.1)$ & $123(100)$ & & \\
\hline & $>7 D$ & $15(78.9)$ & $4(21.1)$ & $19(100)$ & & \\
\hline
\end{tabular}

\section{Discussion}

Pneumonia in children under five years of age is a leading cause of morbidity and mortality in India and other developing countries4,7. Identifying risk factors for childhood pneumonia that are amenable to intervention is of public health importance. In our study, most of the cases were infants (57\%), similar to Cunha et al 20008 which concluded lower age as a risk factor for developing pneumonia. This might be because in young children immunity is not well established, and also because of narrow airways, relatively short bronchial trees, and incomplete development of lungs9. Males outnumber the females in our study, this might be due to early reporting and hospitalization of a male child. In our study, $73 \%$ of the cases belonged to the urban locality, our hospital is located in Bhopal, this might explain more number of cases belonging to the urban area in our study. The presence of many comorbidities and disease history has been accepted as risk factors for CAP. Children who have a concomitant chronic illness may have their immunity lowered making them more susceptible to severe disease. In our study, $46 \%$ of the cases and only $11 \%$ of the control have a history of LRTI/ asthma/ allergy/ rhinitis/ CHD/ diarrhea in the last 3 months that was statistically significant. In our study, $16 \%$ of cases have a family history of Asthma/Allergy/TB/Rhinitis in comparison to $4 \%$ in the controls that were significant which is in concordance to Mahalanabis et al 200210 who concluded that history of asthma in siblings or family were 2.4 times more prone to develop pneumonia.
Somaya Aftab et al 201712 had concluded that the inability to initiate and continue exclusive breastfeed in the baby increases the risk of pneumonia. Similarly, In our study Failure to exclusively breastfeed for 6 months has been shown to increase the risk of CAP. In our study bottle feeding appears to increase the risk of CAP, as $50 \%$ of the cases were bottle-fed in comparison to $20 \%$ in control groups and this difference was found to be significant. C J Watkins 1979 reported fewer episodes of acute pneumonia in children who were breastfed than in children who were bottle-fed13. The synergism between malnutrition and pneumonia is well known6. Our study also concludes weight for age less than -3SD as a risk factor for developing pneumonia.

Incomplete immunization had shown to be a risk factor for CAP. It has been an undisputed fact that childhood immunizations are protective against childhood illnesses. In the present study, $28 \%$ of the cases of CAP were incompletely immunized in contrast to $5.6 \%$ in the controls.

Mahalanabis et al 2002 in Calcutta concluded that the poor economic status of parents was associated with a nearly fivefold increased risk of pneumonia10. Our study has also reproduced a similar result as around $50 \%$ of the cases belong to the lower or upper lower class in contrast to $11 \%$ in the control group. In our study lower educational status of parents was found to be associated with CAP. Victoria et al 199414 also drew a similar association between the lower educational status of parents and the risk of pneumonia, hospitalizations, and mortality. 
Studies from different parts of the world had reported indoor air pollution caused by indoor smoking and the use of biomass as a cooking fuel to increased respiratory morbidity in children. The present study also concludes indoor air pollution as a risk factor for CAP. In our study, $43 \%$ of pneumonia cases were exposed to indoor smoke in comparison to $14 \%$ in controls and this association was found to be significant. The severity of pneumonia was also analyzed in the present study for different risk factors, only previous treatment and delayed presentation were the two factors found to increase the severity of pneumonia. In the present study among those who were previously treated $78 \%$ landed up with severe pneumonia in comparison to $47 \%$ in those who presented directly. Those who were previously treated might be severely ill from the start of the illness itself which can explain higher severity among the previously treated children. However, we did not have the details of their previous treatment which might have been inadequate. Somaya Aftab 201712 In their study also concluded that delay in presentation is a risk factor for complicated pneumonia.

\section{Limitations}

The present study is not devoid of the limitation. As the present study was hospital-based, hospitalized cases may not be representative of all pneumonia cases in the community, similarly, neighbourhood controls would have offered better comparisons and given the interviewers a chance to observe the housing conditions would have been better instead of hospital-based controls. This type of study design was particularly prone to bias compared with other analytical designs, in the particular selection and recall bias. Our study had a small sample size so there is a need for extensive population-based research.

\section{Conclusion}

Concentrated efforts are needed to strengthen the health facilities and immunization coverage in the population. Public awareness should also be increased to improve the better utilisation of available resources. Improving the socio-economical status of people are welcome, this can take a long time to bear fruit. We should promote and ensure the implementation of several preventive measures that will have a major impact on the prevalence and complications of malnutrition and infection.
Reduction in indoor air pollution can be achieved by further promoting LPG as a fuel.

\section{What does the study add to the existing knowledge?}

Continued efforts toward appropriate case management, actions directed against the above risk factors may help to prevent the major cause of deaths of children younger than 5 years.

\section{Authors Contribution}

Dr. J. Dixit: Topic selection, Study design, questionnaire preparation.

Dr Dinesh Mekle: Study design, Questionnaire preparation, Data analysis.

Dr Pratyush Dwivedi: Data collection, Entry of data and Analysis.

\section{Reference}

01. Revised WHO classification and treatment of childhood pneumonia at health facilities EVIDENCE SUMMARIES. 2018.

Available at: [Article] [Crossref]

02. Garenne M, Ronsmans C, Campbell H. The magnitude of mortality from acute respiratory infections in children under 5 years in developing countries. Bulletin of World Health Organization. 1992;45;180-91.

[Crossref]

03. Nair H, Simões EA, Rudan I, Gessner BD, AzzizBaumgartner E, Zhang JS, et al. Global and regional burden of hospital admissions for severe acute lower respiratory infections in young children in 2010- a systematic analysis. Lancet. $2013 ; 381 ; 1380-90$.

doi: $10.1016 / \mathrm{S} 0140-6736(12) 61901-1 . \quad$ [Crossref]

04. Available at: [Article] [Crossref

05. Wardlaw T, Johansson E W, Hodge M. Pneumonia- The forgotten killer of children. Bulletin of World Health organization. 2006;7;444.

Available at: [Article] [Crossref] 
06. Rudan I, Boschi-Pinto C, Biloglav Z, Mulholland $\mathrm{K}$, Campbell H. Epidemiology and etiology of childhood pneumonia. Bull World Health Organ. 2008;86(5)408-416.

doi: $10.2471 /$ blt.07.048769. [Crossref]

07. Available at: [Article] [Crossref]

08. Cunha AL, Margolis PA, Wing S. Community economic development and acute lower respiratory infection in children. jhpdc.

Available at: [Article] [Crossref]

09. Tupasi TE, Mangubat NV, Sunico ES, et al. Malnutrition and acute respiratory tract infections in Filipino children. Rev Infect Dis. 1990;12;S1047-S1054.

doi: $\quad 10.1093 /$ clinids/12.supplement_8.s1047

[Crossref]

10. Mahalanabis D, Gupta S, Paul D, Lahiri M, Khaled A. Risk factors for pneumonia in infants and young and the role of solid fuel for cookinga case-control study. Epidemiol Infect. 2002;129;65-71 doi: 10 .

1017/s0950268802006817 [Crossref]
11. Lang T, Lafaiz C, Fassin D, Arnaut I, Salmon B, Baudon D, Ezekiel J. Acute respiratory infections: A longitudinal study of 151 children in Burkina Faso. Int J Epidemiol. 1986;15;55360. doi: 10.1093/ije/15.4.553 [Crossref]

12. Sommayya Aftab, Iftikhar Ejaz, Umar Waqar, Humayun Iqbal Khan, Asif Hanif, Amir Usman, Asma Mushtaq, Ilyas Muhammad Nadeem2, Holifa Saheera Asmara2, Atif Amin Baig3 Risk factors for childhood pneumonia in north eastern pakistan- a case-control study. MJPCH. 2016 jun-Dec;22;26-34.

Available at: [Article] [Crossref]

13. Watkins CJ, Leeder SR, Corkhill RT. Journal of Epidemiology and Community Health. BMJ. $1979 ; 33(3) 180-182$.

[Crossref]

14. Victora CG, Fuchs SC, Flores AC, Fonseca W, Kirkwood B. Risk factors for pneumonia among Brazilian children in a metropolitan area. Paediatrics. 1994;93;977-985.

[Crossref]

15. Hemagiri K, Sameena A R B, Aravind K, Khan W, Vasanta SC. Risk factors for severe pneumonia in under five children $-\mathrm{A}$ hospital based study. Int J Res Health Sci. 2014 Jan31;2(1)47-57. Available from [Article] [Crossref] 